\title{
THE CARDIOVASCULAR SYSTEM IN GARGOYLISM
}

\author{
BY \\ STÙART LINDSAY \\ From the Division of Pathology, University of California Medical School, San Francisco, California \\ Received June 8th, 1949
}

Of interest to cardiologists is a large group of rare systemic diseases in which involvement of the cardiovascular system may produce clinical evidence of cardiovascular disease, or may lead to cardiac failure (Weiss, 1939). An attempt has been made to outline the basic clinical, laboratory and pathological features of a few of these processes (Saphir, 1942; Weiss et al., 1943; Lindsay, 1946). The accompanying cardiac manifestations may then be correctly interpreted as a part of a generalized disease, and thus be differentiated from the more common' forms of cardiac disease. The importance of an accurate ætiologic classification of these rare diseases has been emphasized previously (Weiss et al., 1943) since factors of specific therapy must be considered.

Gargoylism, a rare disease of infancy and childhood, has been shown to belong to this group of obscure, miscellaneous systemic processes. In recent pathological studies of gargoylism, it was found that the heart and vascular apparatus are often significantly involved in this diffuse disease (Lindsay et al., 1948), and furthermore that a high percentage of children with gargoylism have clinical evidence of cardiovascular disease or die from cardiac failure.

It is the main purpose of this report (1) to review the clinical manifestations of gargoylism, stressing those of cardiovascular origin, (2) to summarize the available pathological data, particularly in regard to the heart and vascular system and (3) to record an additional case of gargoylism occurring in infancy, in which involvement of the heart by the storage process was responsible for acute fatal myocardial failure.

\section{General Characteristics}

Previous pathological studies have shown that gargoylism is a generalized disease in which almost all tissues in the body are the sites of an abnormal storage process (Kressler and Aegerter, 1938; Strauss, 1948; Lindsay et al., 1948). Unlike the majority of storage diseases in which the reticuloendothelial system alone shows extensive involvement, gargoylism is characterized by the deposition and retention of a macromolecular substance mainly in parenchymal cells and in fibroblastic and other supporting connective tissues. In the earlier studies on limited autopsy material (Ashby et al., 1937) it was generally agreed that gargoylism was a lipid storage process, though Kressler and Aegerter (1938) found variable histochemical staining reactions. Washington (1940) proposed the term lipochondrodystrophy. More recent pathological studies have shown that the material stored in the altered cells gives the histochemical reactions of glycogen. Furthermore there is evidence that this carbohydrate is combined with protein as a glycoprotein (Lindsay et al., 1948).

There is no evidence of altered carbohydrate metabolism in gargoylism, except for the recording of abnormal galactose tolerance tests in a few instances. This indicates that the stored carbohydrate represents a complex macromolecular substance which can not be disposed of or degraded by the tissue cells and does not enter the carbohydrate turnover of the body. 
Clinical evidence of the disease is not generally apparent until the stored material accumulates in quantities sufficient to alter the structure or interfere with growth of the skeletal or other tissues. While signs of the disease may be present at birth, usually these do not make their appearance until near the end of the first year of life.

Recurrence of the disease in families has been noted often, even in as many as three generations. Halperin and Curtis (1942) believe that the disease is most likely due to the action of a single recessive autosomal gene. The inheritance of glycogen disease (Von Gierke's disease) is also believed to be due to a Mendelian recessive characteristic (Abramson and Kurtz; 1946).

Over 150 cases of gargoylism have been recorded; the bibliography of the majority of these have been collected elsewhere (Lindsay and Reilly, 1948, and Strauss, 1948).

\section{Clinical Picture of Gargoylism}

These children usually have such a characteristic appearance as to suggest a familial relationship (Fig. 1). The external manifestations ordinarily appear at 1 to $1 \frac{1}{2}$ years of age, though one of our patients showed the typical facies at 3 months. In one recorded case, the child was described as

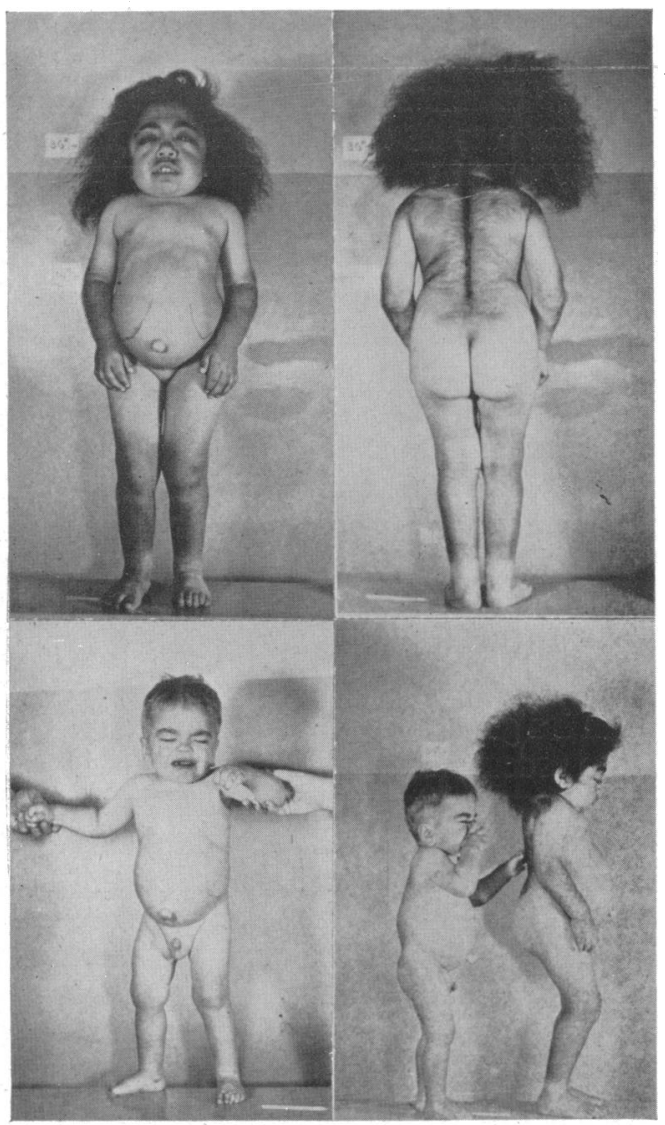

FIG. 1.-Typical gargoylism showing dwarfism, hirsutism, hepatosplenomegally, umbilical hernia, and skeletal deformity. The boy is 3 years of age and the girl 13 years of age. having a repulsive appearance with a deformed skull at birth (Ashby, Stewart, and Watkins, 1937). Some children had corneal clouding at birth. The grotesque appearance of these little creatures led to the application of the term gargoyle by Ellis and his co-workers (1936).

There is relative enlargement of the head. The facial features are coarsened and the nasal bridge is depressed. The eyebrows are thick. The eyes appear protruding. The mouth is usually open and almost filled with an enlarged protruding tongue. The external ears appear enlarged and the aural cartilage is often soft and unusually flexible.

The alterations of the skeleton are particularly striking. The stature is short, mainly due to shortening of the legs. The neck is usually shortened and thickened. There is often an increase in the anterior-posterior diameter of the chest, at times with unusual prominence of the sternum and posterior bowing of the costal cartilages. Dorsal kyphosis near the thoracolumbar junction was present in 12 of one group of 14 patients. These patients stand with a partial crouch, with the thighs and knees partially flexed. There is similar flexion of the elbows and the hands are usually in ulnar deviation. The small joints of the wide stubby hands and feet are held in a flexed position giving a clawed appearance.

Shortening of the mandibular rami with increased obtuseness of their angles is often associated with widely spaced, peg-shaped teeth. 
The abdomen is protuberant. The liver and spleen are enlarged, and are usually palpable by the end of the first year; they are smooth and firm. An umbilical hernia is almost invariably present, and inguinal hernias have been present in a number of male patients.

Most children with gargoylism develop cloudiness of the corneas, and progressively diminishing vision. This clouding is due to the presence of punctate refractile deposits (slit lamp) mainly in the deeper corneal fibres. Reduction in ability to hear or even total deafness usually appears by the 6 th to 12 th month.

Hirsutism of the trunk and extremities, as well as of the scalp, neck, and eyebrows has been present in over half the patients.

One of the most prominent findings, often antedating the skeletal and other external manifestations, is chronic nasal infection with profuse nasal discharge and severe nasal obstruction. This is probably responsible for the frequency of pulmonary infections so often noted in these children.

Most of these children show progressive mental deficiency beginning at about 6 to 18 months after the onset of the other clinical manifestations of the disease. Three of 15 patients whose intelligence was tested had normal mentality. One of the three died at the age of 11 years, and pathologic examination of the brain showed storage involving only some of the connective tissue cells of the central nervous system (Reilly and Lindsay, 1948). The brains of those with retarded mental growth have shown extensive storage of the macromolecular substance in the cytoplasm of almost all portions of the central and peripheral nervous system, involvement sufficient to account for the usual clinical evidence of mental disease (Lindsay et al., 1948).

\section{LABORATORY FINDINGS IN GARGOYLISM}

Examination of the blood in our series of patients (Reilly and Lindsay, 1948; Lindsay et al., 1948) has shown mild hypochromic anæmia in 10 of 16 patients. Six had white blood counts of 5000 per cu. $\mathrm{mm}$. or below. At times, some of these patients have shown a relative lymphocytosis. In eight patients, abnormal dark-violet granules (Wright's stain) have been demonstrated in the white blood cells (Reilly, 1941). These are found mainly in the neutrophilic leucocytes. The number of involved cells fluctuates widely. More recent studies (Lindsay et al., 1948) have suggested that these granules may consist of the same carbohydrate material widely stored in other tissue cells.

Urinalysis gave normal findings in all the cases. Reducing substances have never been demonstrated in the urine. In five children, blood lipid analyses were done. One showed lipæmia and hypercholesteræmia. A variety of other chemical examinations of the blood showed nothing abnormal as a rule. In one child a hippuric acid test gave abnormal results. In another, there was prolonged retention of galactose in the blood after intravenous injection. With that exception, carbohydrate tolerance tests gave normal findings.

Serological tests for syphilis were done in 14 of the patients; all gave negative results.

\section{ROENTGENOGRAPHIC FINDINGS}

In well developed cases, the skeletal alterations of gargoylism are characteristic and have been described in detail elsewhere (Reilly and Lindsay, 1948). Changes in the skull include enlargement and shallowness of the sella tursica and prominence of the frontal bones. The scapulas are widened, and the ribs are broadened and distorted. Notch-like irregularities of the lower thoracic and lumbar vertebral bodies often produced dorsal kyphosis. Pronounced lesions are demonstrated in the extremities, where the shaft of the long bones tends to be short and broad with bizarre central swellings. There is delay of epiphyseal maturation and the epiphyseal plates are usually flat and deformed. Those of the radius, ulna, and tibia are often angulated. Irregular widening of the phalanges, metacarpals, and metatarsals account for the claw-like hands and feet of these children. Two patients had encephalograms; one showed frontal cerebral atrophy, and the other internal hydrocephalus. 


\section{Histological Lesions in GaRgoylism}

The characteristic cellular lesion in gargoylism is enlargement due to swelling of the cytoplasm. The latter may be almost entirely clear and colourless and surrounded by a thin cellular membrane. In some cells, the central perinuclear portion of the cell is occupied by a clear vacuolated space, surrounded by condensed peripheral cytoplasm. In still other cells, the cytoplasm may have a coarse or fine granularity which represents a fragmented residual cytoplasmic network surrounding tiny vacuolated spaces. Some nerve cells show this alteration only in one portion of their cytoplasm.

A variety of cell types are included in the storage process. Epithelial cells, particularly of the liver, are markedly altered. The epitheliu m of the skin and its glands, and the anterior lobe of the pituitary gland are among the other epithelial tissues involved. Nerve cells of all portions of the central and peripheral nervous system are sites of deposition. Reticuloendothelial cells, both fixed and wandering, show the same vacuolization of the cytoplasm, particularly in the spleen and lymph nodes. The most striking tissue changes are observed in the mesodermal connective tissues. Fibrocytes, chondrocytes, and osteocytes all show enlargement and vacuolization of their cytoplasm. Since the intercellular substances supporting these cellular elements are derived from their cytoplasm, and since the cellular cytoplasm is altered due to the storage process, it is not surprising that the intercellular connective tissue substances have an abnormal appearance. In some situations, particularly in the cardiovascular system, the storage process in fibroblastic cells was associated with increased amounts of altered collagenous intercellular substances. Most collagenous fibres had lost their normal fibrillary characteristics, and appeared swollen and homogeneous. Osteomucin and chondromucin frequently had a fibrillary or mucoid appearance and were poorly formed. These alterations of connective tissues, associated with lack of normal osteoblastic activity, particularly at epiphyseal lines, appears to be a prominent factor in the retarded skeletal growth in these children.

\section{Cardiovascular Symptoms and Signs}

In the published reviews of gargoylism, cardiovascular signs and symptoms, occasionally with death from cardiac failure, are frequent (Reilly and Lindsay, 1948, and Strauss, 1948). While Ellis and his co-workers (1936) mentioned no cardiovascular abnormalities in the 15 patients reviewed by them, Washington (1940) recorded three cases of gargoylism with death resulting from cardiac failure.

The clinical records of 16 cases of gargoylism previously reported (Reilly and Lindsay, 1948) were reviewed for evidence of cardiovascular disease: 2 presented symptoms that may have been of cardiovascular origin, 11 had physical or roentgen signs of cardiovascular disease at some time during the course of their illness, and of the 8 fatal cases with autopsies, 4 died of cardiac failure.

Of an additional 16 reported fatal cases, 3 were reported as presenting symptoms of cardiac disease, and 5 had clinical signs of cardiac abnormality. In several reports, the cardiac status was not mentioned. Nine of the 16 additional reported patients who succumbed to their disease appear to have died of cardiac failure. The recorded cardiovascular signs and symptoms and cause of death in all these cases have been summarized in Table I.

\section{Pathological Cardiovascular Lesions in Gargoylism}

Gross Lesions. Of the 25 patients with gargoylism on whom an autopsy was done, the weight of the heart was recorded in 16; in 13 of these, there was cardiac hypertrophy. The weight of the heart varied from 10 to 147 grams more than the average normal weight for the patient's age. In two instances, the weight of the heart was increased two and three times respectively. In two cases, the cardiac weight was within normal limits, and in one the weight was slightly less than normal. Considering that dwarfism is usual, the degree of cardiac hypertrophy is generally extreme.

In 4 of the 25 patients, there was opaque thickening of the epicardium, in one instance involving 
TABLE I

Cardiovascular Findings in Gargoylism

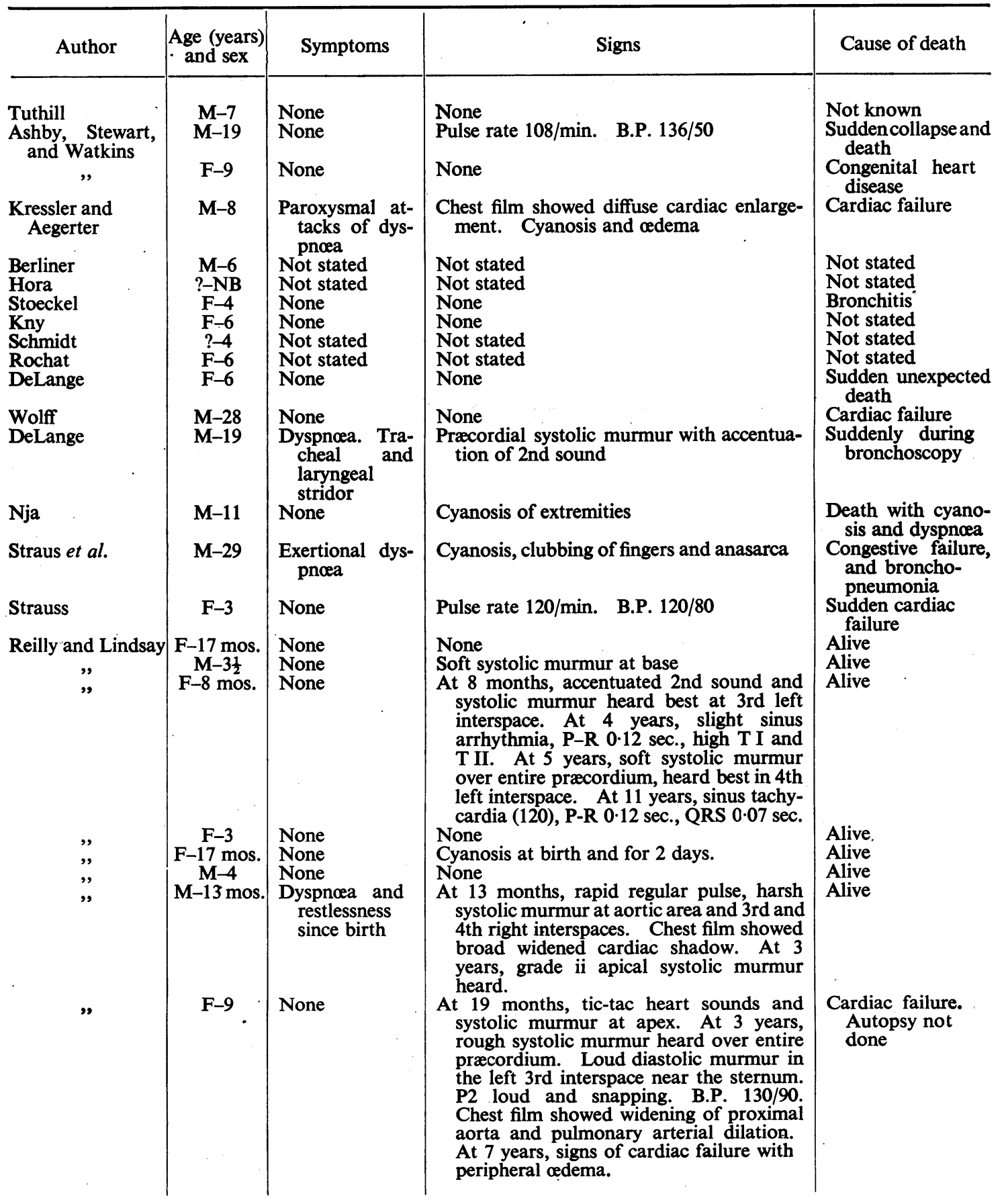


TABLE I-CARdiovascular Findings in GARgoYlism-continued

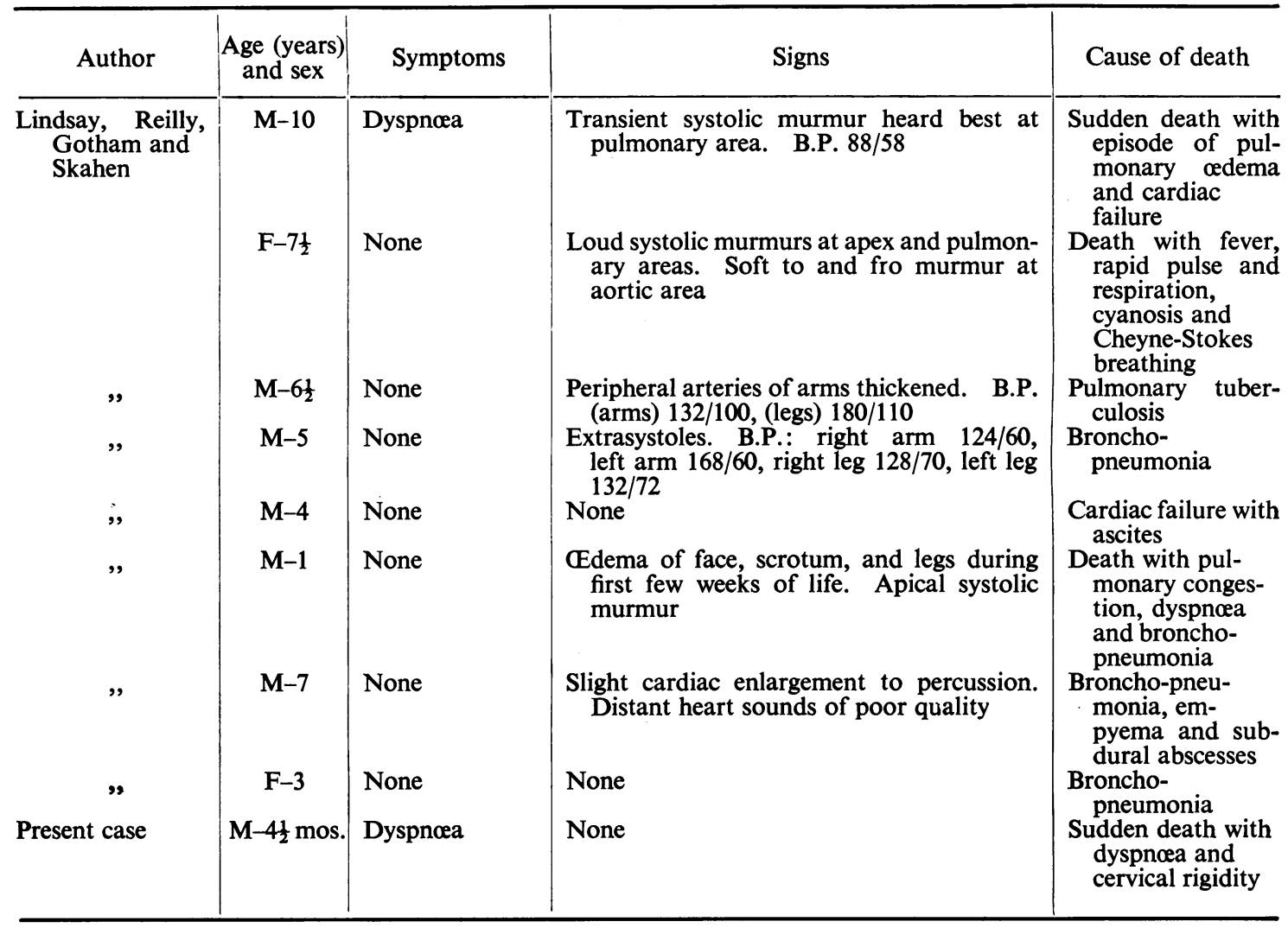

both left and right ventricular surfaces. In three instances, there was similar diffuse thickening of the endocardium, mainly of the ventricles and especially prominent near the mitral valve.

Significant left ventricular hypertrophy was described in seven of the autopsied cases. In one there was hypertrophy of the right ventricular wall as well. The myocardium was pale and firm in one, and in the case described in this paper was soft and greyish red. The presence of myocardial fat was mentioned in one case.

The valvular lesions are probably the most striking cardiac abnormalities seen in this disease, and were described in 14 of the 25 recorded fatal cases. In one, the mitral and tricuspid valves were described as " congested" (Ashby, Stewart, and Watkins, 1937), and in one the valvular lesion was described only as "chronic endocarditis" (Stoeckel, 1941). More adequate descriptions are available in the remaining 12 cases.

In the one reported by Kressler and Aegerter (1938) the mitral valve was thickened, scalloped, and showed orange pigmentation of the cusps; the edge of the posterior mitral leaflet and the base of the aortic valve were calcified. Wolff's case (1942) showed chronic endocarditis of the aortic, mitral and tricuspid valves with aneurysmal dilatation of the margins of the mitral and tricuspid valves. In one of DeLange's patients (1944), the mitral cusps were diffusely thickened and stiffened, but had smooth surfaces; there was shortening and fibrous thickening of the mitral chordæ tendineæ. The tricuspid valvular cusps were thickened, but still flexible. The pulmonic valve was normal, but the free edge of the aortic valvular cusps was thickened. Nja's case (1945) had thickening of both the aortic and mitral valves; in the latter, the thickening was nodular and the attached chordæ tendineæ were shortened and thickened. In the case recently reported by Strauss (1948), there were numerous $3 \mathrm{~mm}$. nodules with smooth surfaces, distributed along the mitral and tricuspid 
valves at the insertions of the chordæ tendineæ, which were short and thick; these nodules had a fibrous consistency. The aortic and pulmonic valves were odematous and fleshy.

In the material examined at the University of California Hospital, seven of nine patients (including the one presented in this paper) had valvular lesions. In all instances, the mitral valve showed the characteristic lesion (Fig. 2). In two, the tricuspid valve was similarly involved, and in one the aortic and mitral valves were both altered. In another case in this series, all the valves were affected by the pathological process.

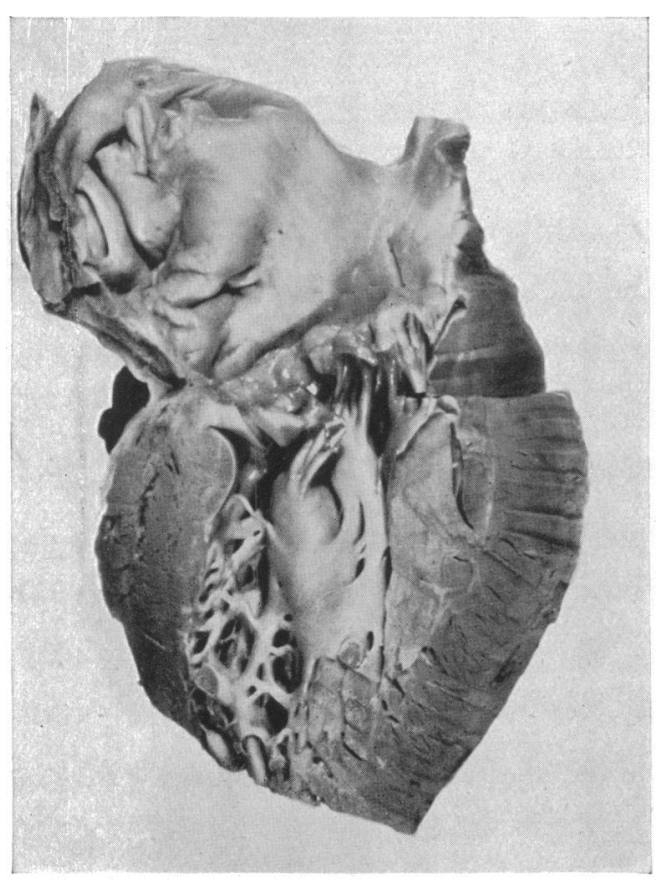

FIG. 2.-Mitral valve with nodular thickening and shortening of chordæ tendineæ.

Alteration of the mitral and tricuspid valves is characterized generally by a nodular fibrous thickening along the free edge and line of closure of the valve. These nodules are usually coalescing and have a glistening translucent appearance. They vary between $1 \mathrm{~mm}$. and $3 \mathrm{~mm}$. in diameter. The diameter of the chordæ tendineæ of these altered valves is several times the normal diameter; these structures are contracted and shortened, and have an opaque fibrous appearance. Mitral stenosis was the result of this process in one case.

When involved, the aortic and pulmonary cusps show a rolled free edge. While the thickening has the moist fibrous appearance of the mitral valvular lesion, the margin of the valve is not usually nodular, and may be slightly retracted.

Of the reported fatal cases of gargoylism, three have shown gross evidence of coronary insufficiency. Thus in Strauss's case (1948), the coronary arteries were widely patent, but had stenotic, slit-like orifices. In two (Lindsay et al., 1948), pronounced coronary arterial thickening could be seen. In one of these, the coronary arterial system appeared prominently on the epicardial surface as rigid white cords. In both instances, the intima was greatly thickened and consisted of a layer of grey, glistening translucent fibrous tissue; this left small pin-point or slit-like lumens. The altered intima contrasted sharply with the more compact, opaque medial layer.

Of the 25 recorded autopsies, macroscopic aortic lesions were described in 7 instances. Kressler and Aegerter (1938) found orange intimal streaking of the ascending aorta. In the case of DeLange et al. (1944) there was linear lipid infiltration of the posterior aortic wall. Strauss (1948) described thickening of the aorta and its major branches; the aortic intima was white, wrinkled, and contained yellow plaques.

In the group of eight patients previously reported, gross aortic lesions were described in three (Lindsay et al., 1948). In the aorta of one ten-year-old boy, there were three small intimal plaques just distal to the valve. In the case of a four-year-old boy, there were four oval elevated yellow plaques just distal to the valve. In the third case, numerous small yellow plaques were found just distal to the valve, and there were small linear yellow streaks in the thoracic aorta, most numerous about the intercostal arterial ostea. In addition, there were a few longitudinal streak-like plaques which were grey in colour in this segment of the aorta.

Gross alteration of other vessels had been described in only two cases. In one (Strauss, 1948) there was slight thickening of the pulmonary arterial branches. In another, one of the main pancreatic arteries showed translucent intimal fibrous thickening (Lindsay et al., 1948).

Visible renal alteration has been described in a few instances. Where the renal weights have 
been recorded, these have been close to the normal average weight for the age with one exception. In relation to body size, the kidneys were often enlarged. Generally the gross appearance has not been significantly altered. In two cases the cortical layers showed yellowish-pink pallor.

Microscopic Lesions. Microscopic pathological lesions in the cardiovascular system of a fairly uniform and characteristic type have been described in 12 patients. Connective tissues of the pericardium, myocardium, endocardium, valves, and coronary vessels have shown a similar alteration. The fibroblastic cells were swollen and enlarged. Their cytoplasm was clear, vacuolated, or granular. There was an increase in the amount of intercellular collagenous stroma, and this material usually had undergone hyaline or mucoid changes. The normal fibrillary characteristics were lost, and the fibres often appeared œdematous. The cellular swelling, and the alteration of the intercellular collagen often produced a pseudocartilagenous appearance in the involved cardiac connective tissue.

The fibrous thickening and cellular alteration in the valves and endocardium was greater than elsewhere in the heart, and accounted for the nodular deformity of the valves and the widening and thickening of the chordæ tendineæ. In a few instances minimal chronic inflammatory cellular infiltration and either large or small calcific deposits have been present in the altered valvular connective tissue. In two cases, lipid droplets have been demonstrated in some of valvular fibroblasts, but the amount of this material did not account for the degree of cellular enlargement. DeLange et al. (1944) were unable to demonstrate the presence of glycogen in the altered cells.

Myocardial alteration has been described in several instances. Kressler and Aegerter (1938) described vacuolization of the myocardial nuclei and fibres. There was atrophy and fraying of some cardiac muscle fibres associated with an increase in myocardial connective tissue in one of DeLange's cases (1944). Strauss (1948) found atrophy of myocardial fibres with replacement by large vacuolated cells; other fibres were hypertrophied. Three of our cases (Lindsay et al., 1948) showed vacuolization of the myocardial fibres; in one instance the vacuoles contained bluish granular material.

The coronary arterial system shares in the connective tissue alteration in gargoylism. Strauss (1948) found segmental medial thickening of the medium size coronary arterial branches; the media contained large vacuolated cells. Four of the cases from this clinic have shown intimal fibrous thickening of the main coronary arteries and the major branches. In three cases this process greatly narrowed the arterial lumens, and two of these died of cardiac failure. The thickened intimal layer consisted of moderately dense wavy collagenous fibres with a concentric arrangement. The fibres were usually swollen, and appeared less fibrillary than normal. Lying between the fibres were elongated clefts containing large swollen fibroblasts with clear cytoplasm. There was pressure atrophy of the surrounding media, and the adventitial connective tissue usually showed changes similar to those of the other cardiac connective tissues.

The storage reaction involves the aortic wall as well as the heart in this disease. There was intimal thickening and swelling of the medial connective tissue cells in the cases described by DeLange (1944) and Strauss (1948). In five of our cases aortic microscopic lesions have been demonstrated. The intima was thickened and composed of hyalinized collagenous connective tissue containing distorted vacuolated fibroblastic cells. In a few instances, the superficial part of the intima contained groups of foamy macrophages in which lipid material could be demonstrated. The elastic tissue fibres of the media were usually very distinct and were separated by fusiform clefts containing altered swollen connective tissue cells (Fig. 3). Some of these cells contained pale greyish blue granular material. The adventitial connective tissue usually had a similar appearance.

In several of the recorded cases, similar though less severe intimal thickening has been described in carotid, mesenteric, pancreatic (Fig. 4) and renal arteries. The medial muscular cells have been vacuolated as well.

While renal lesions have not been described in cases elsewhere, five of the nine fatal cases examined in this laboratory have shown distinctive glomerular alteration of varying degrees 


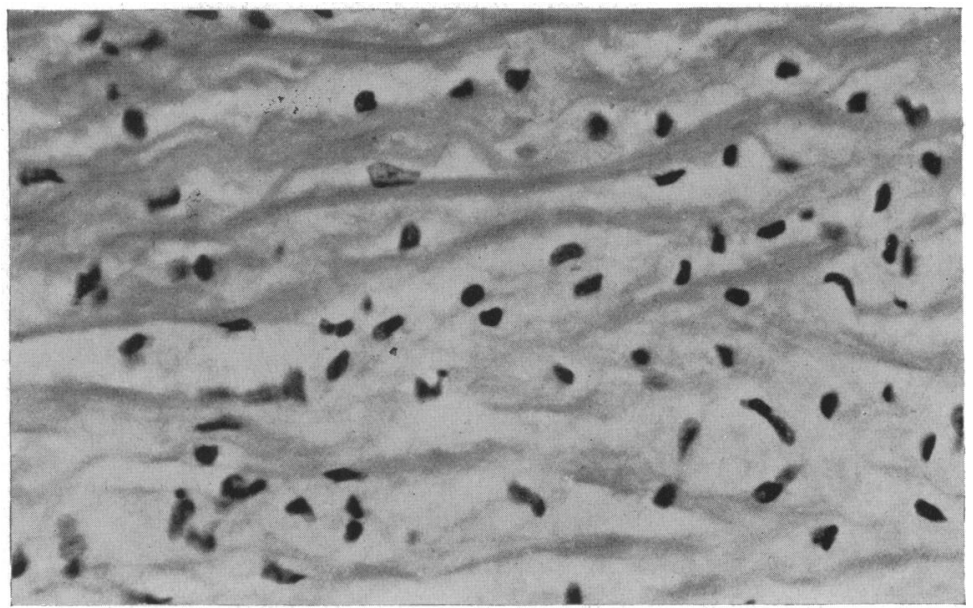

FIG. 3.-Aortic media showing swelling of connective tissue cells. Magnification $\times 500$. Hæmatoxylin and eosin stain.

of severity. These lesions bear resemblances to those of glomerulonephritis. While the frequent chronic recurrent respiratory infection in these patients might well result in glomerulonephritis, the lesion has certain characteristics resembling the other altered tissues in this disease. There are increased numbers of both epithelial and endothelial cells in the glomeruli resulting in glomerular enlargement and narrowing of the capillary channels (Fig. 5). The glomerular tufts are occasionally adherent to each other, and to the glomerular capsules. Some glomeruli have shown epithelial proliferation in the capsules with formation of epithelial crescents. The basement membranes were usually swollen and frayed, and some had deposits of amorphous grey granular

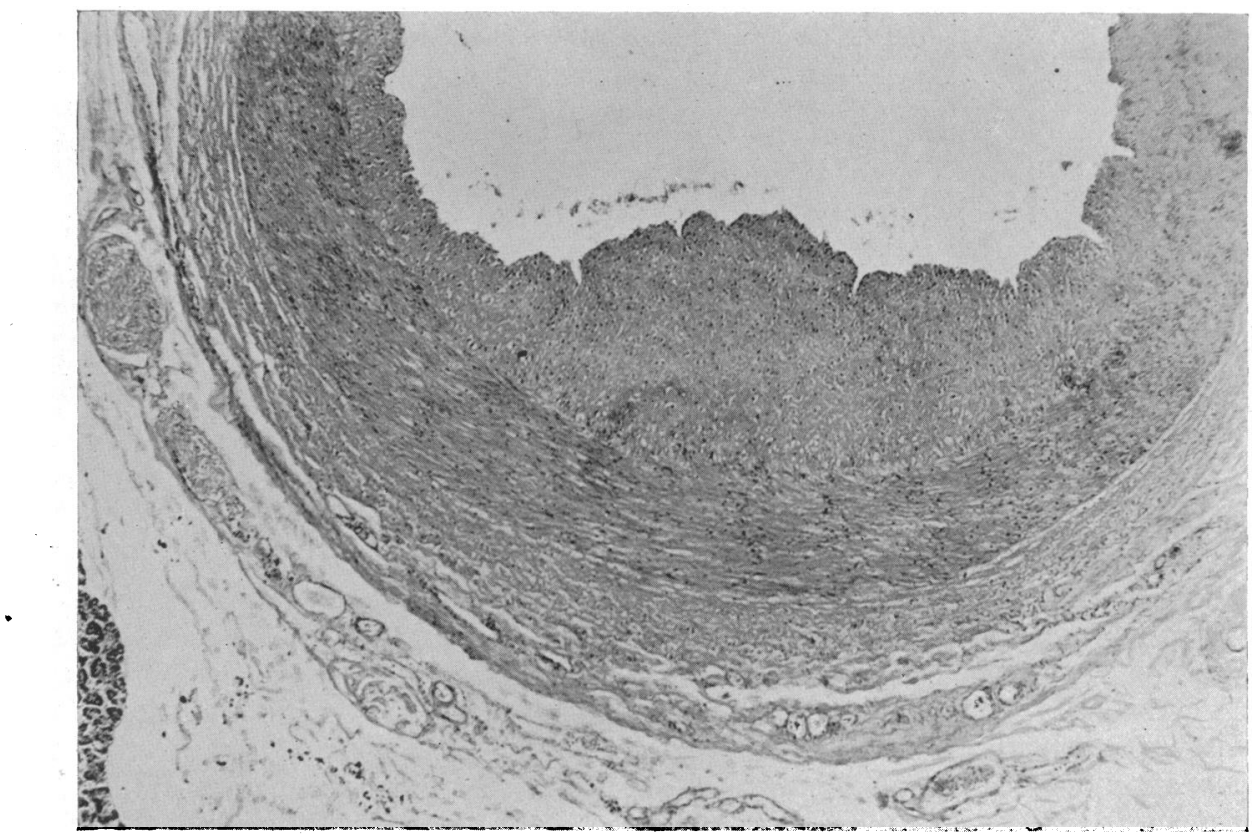

FIG. 4.-Pancreatic artery showing intimal thickening. Magnification $\times 45$. Hæmatoxylin and eosin stain. 
material. There were often desquamated cells and precipitated protein in the glomerular spaces. Abnormal vacuolization of the convoluted tubular epithelial cells frequently accompanied the glomerular lesions. It is of interest to note that one of these children with pronounced glomerular lesions had a phenolsulphonephthalein excretion test of 23 per cent.

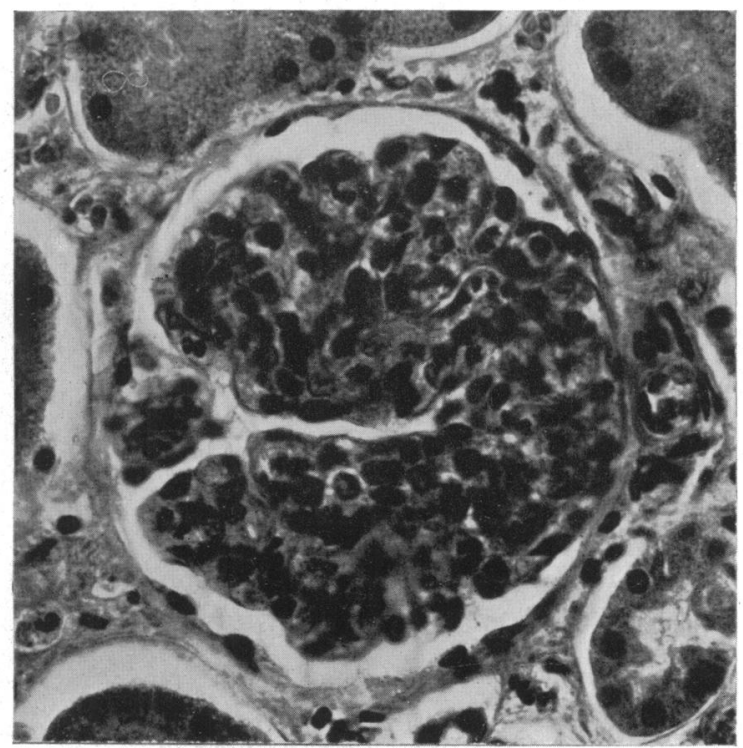

FIG. 5.-Glomerulus showing increased cellularity, decreased vascularity and thickening of basement membrane. Magnification $\times 500$. Hæmatoxylin and eosin stain.

\section{ExtraCardiac Factors Contributing to Cardiac Embarrassment}

There are several extracardiac factors operating that should be noted as probably contributing to cardiac embarrassment. One is the thoracic deformity, which includes narrowing of the transverse diameter of the chest with anterior prominence of the sternum, posterior bowing of the costal cartilages and an increase in the dorsal curvature of the thoracic spine. Elevation of the diaphragm by the enlarged liver and spleen appears to diminish further the volume of the thoracic cavity.

Chronic interstitial pneumonitis, usually with histologic evidence of the abnormal storage reaction in the pulmonary tissues is a common lesion in gargoyles. It is probably secondary to the common chronic nasopharyngeal inflammation which in turn is secondary to the bony deformities of the nose and nasal passages.

Anæmia, at times of severe grade, is a third factor that may be responsible in part for the cardiovascular signs and symptoms in this disease.

\section{DiAGNOSIS}

While the fully developed syndrome of gargoylism should present no diagnostic difficulties, some cases have not shown the complete clinical picture. Thus mental retardation or corneal clouding has been absent in some of the recorded cases that otherwise had the typical facies, hepatosplenomegaly, dwarfism, and skeletal deformities. These changes do not occur together in any other disease. The external appearance of these children resembles that of cretinism; both at this clinic and elsewhere, substitution thyroid therapy has shown little if any effect on growth. While the serological reactions have been consistently negative, some patients have been given antiluetic therapy because of the resemblance of the cloudy corneas to those of congenital syphilis. Such therapy has been without benefit. A diagnosis of hypertelorism has been suggested in some instances 
because of the increased intra-orbital distance. Because of the frequency of demonstrable systolic murmurs along the left sternal border, 4 of 16 patients with gargoylism reported from the University of California Medical School were suspected of having a congenital interventricular septal defect. Pulmonary stenosis was suspected in one. Rheumatic heart disease was not considered in the differential diagnosis in this group of cases.

\section{Similarities of Pathological Cardiovascular lesions to those of Glycogenosis}

The pathologic lesions in the heart and other tissues in gargoylism have some resemblance to those of glycogen disease (Von Gierke's disease). Both these conditions differ from the other storage processes in that the glycoprotein or glycogen is deposited mainly in parenchymal or fibroblastic cells rather than in reticulo-endothelial cells.

Since Von Gierke's pathological description of glycogen storage disease in 1929, it has become apparent that there were two principal forms of the disease: (1) the type characterized by excessive storage of glycogen in the liver and (2) glycogen storage disease involving the heart; the latter appears to include true excessive glycogen storage in the cardiac muscle fibres and congenital cardiac rhabdomyoma. The differentiation of these lesions has recently been reported. Haymond and Giordano (1946) have reviewed the subject of glycogen disease of the heart, and stressed the characteristic vacuolization of the cardiac muscle fibres. Mason and Anderson (1941) collected 11 cases demonstrating that these vacuoles represented glycogen deposits, and ten of their cases were infants who died from myocardial failure and pneumonia between 5 and 8 weeks of life. Sudden death has been reported (Van Creveld, 1939). While the cardiac enlargement may be enormous, generally there is no alteration of the pericardium, endocardium, valves, or coronary blood vessels. However, glycogen accumulation in the walls of arteries and veins has been described (Hueper, 1942). The myocardium has been described as pale brownish or reddish-pink or having greyish streaks. In the nodular form of glycogen storage disease of the heart, Haymond and Giordano (1946) showed additional histological changes similar to those occurring in gargoylism. In the involved areas, the small coronary arterial twigs showed mild perivascular fibrosis and fibrous intimal thickening. Loose areolar connective tissue with oval vesicular nucleii had replaced many of the myocardial fibres. This connective tissue somewhat resembled the subendocardial and intimal coronary arterial fibrosis of gargoylism.

\section{CASE REPORT}

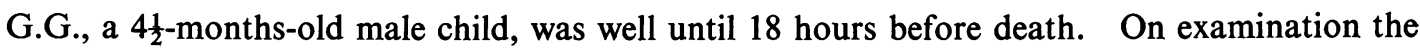
child was found to have respiratory difficulty and stiffness of the neck. Since there was no improvement in the infant's condition by the following morning, admission to hospital was advised. En route to the hospital, the infant became unconscious and expired.

Autopsy Report. The autopsy was performed at the San Francisco Coroner's Office seven hours after death by Drs. Jeanne I. Miller and Henry D. Moon. The infant was large, and appeared well developed and nourished. External manifestations suggestive of gargoylism were not noted. The fontanelles were slightly depressed.

The peritoneal cavity contained approximately $50 \mathrm{ml}$. of clear serous fluid. The pleural cavities contained small amounts of sanguinous fluid; the pericardial cavity was normal.

The heart was enlarged and weighed $90 \mathrm{~g}$. after fixation in 10 per cent solution of fomaldehyde U.S.P. The diameter of the heart was greater than half the transverse diameter of the thoracic cavity. All the cardiac chamber were dilated and in addition there was hypertrophy of the wall of the left ventricle. The epicardium was slightly opaque and granular, and there was scanty epicardial fat. The myocardium of both the left and right ventricles was soft and had a mottled, greyish-red colour. There was diffuse, opaque thickening of the endocardium of the left and right ventricles. The valves and chordæ tendineæ showed nothing abnormal. The ductus arteriosus was barely 
patent; the foramen ovale was closed. The coronary arteries had a normal appearance. The thoracic aorta showed no coarctation.

The thymus gland weighed $35 \mathrm{~g}$., and measured $5 \times 5 \times 2.5 \mathrm{~cm}$. It appeared normal externally and on section.'

The right lung weighed $120 \mathrm{~g}$., and the left lung weighed $60 \mathrm{~g}$. Both lungs had smooth but deeply congested pleural surfaces. The pulmonary parenchyma showed considerable congestion and intraalveolar fluid. While the tissue was more firm than normal, there was no consolidation.

The liver was of normal size and weight. The anterior edge of the right lobe was sharp. The parenchyma was pale, and pinkish-tan in colour. The spleen weighed $30 \mathrm{~g}$. The capsule and pulp were normal The gall bladder and pancreas showed nothing abnormal. The entire gastroenteric tract was normal, though the mesenteric lymph nodes appeared moderately enlarged. The adrenal glands were normal. Each kidney weighed $30 \mathrm{~g}$. The surfaces were smooth, and the cut surfaces showed normal markings and colour. The calyces, pelves, ureters, bladder, and genital system were normal.

The aorta and bone marrow showed no gross pathological lesions.

The scalp, skull, and dura were normal. The brain weighed $860 \mathrm{~g}$. The meninges appeared normal. The superficial markings and blood vessels appeared normal. Serial coronal sections through the cerebral hemispheres, cerebellum and brain stem showed no lesions.

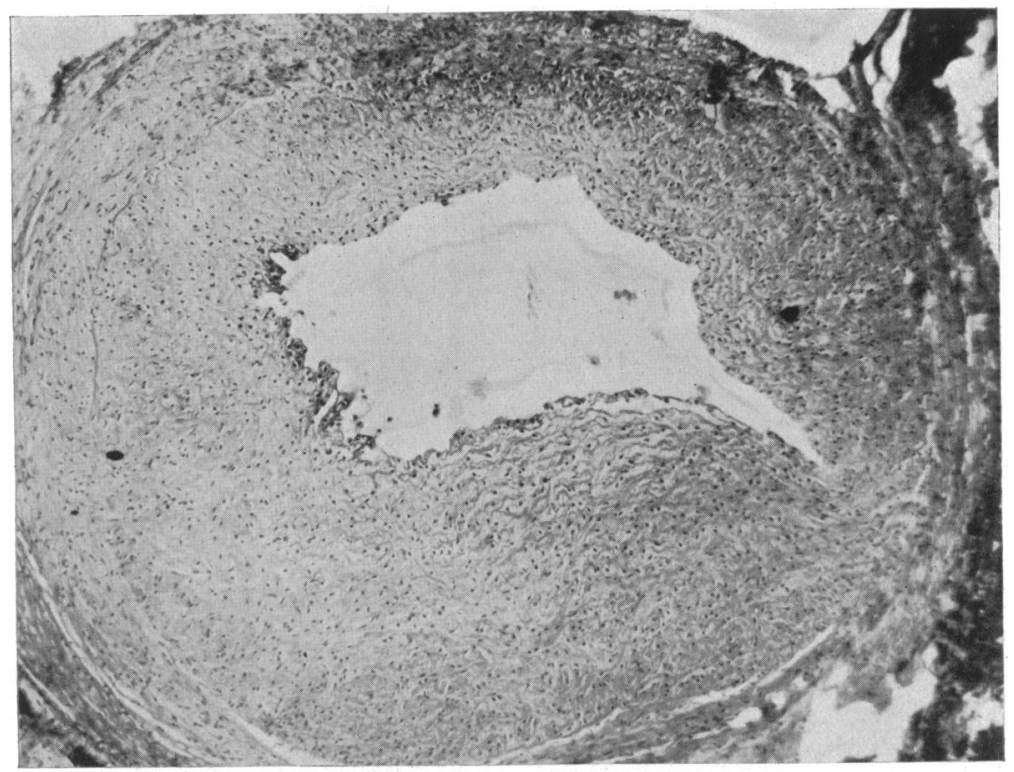

FIG. 6.-Large coronary artery with intimal fibrosis. Magnification $\times 80$. Hæmatoxylin and eosin stain.

Microscopical Examination. Blocks of tissue fixed in 10 per cent solution of formaldehyde U.S.P. and embedded in paraffin were kindly made available for study by Dr. Henry D. Moon.

The main coronary arteries all showed narrowing of their lumens due to marked intimal thickening (Fig. 6). The intimas were composed of concentrically arranged, wavy, collagenous fibres which surrounded fibroblastic cells. The latter had either completely clear or vacuolated cytoplasm. The media of these coronary arteries was narrowed but the adventitial layer was normal.

The opaque thickened ventricular endocardium had a similar histological appearance (Fig. 7). The abundant collagenous fibres were swollen, frayed, and vacuolated. Often they had lost their fibrillary appearance. They enclosed fusiform fibroblastic nuclei which had abundant swollen, clear or vacuolated cytoplasm. The connective tissue of the bases of the mitral and aortic valve was 
similarly altered (Fig. 8). The pericardial layer was not abnormal. Some myocardial fibres were fragmented, and a few had disappeared. There was no vacuolization of their cytoplasm. There was similar alteration of the connective tissue cells of the adventitia of the smaller coronary arteries in the myocardium.

The intima of the proximal portion of the aorta was thickened and fibrotic. It consisted of an irregular network of hyaline collagenous fibres surrounding enlarged vesicular fibroblastic cells. The media had a similar appearance with almost total disorganization of the normal elastic tissue

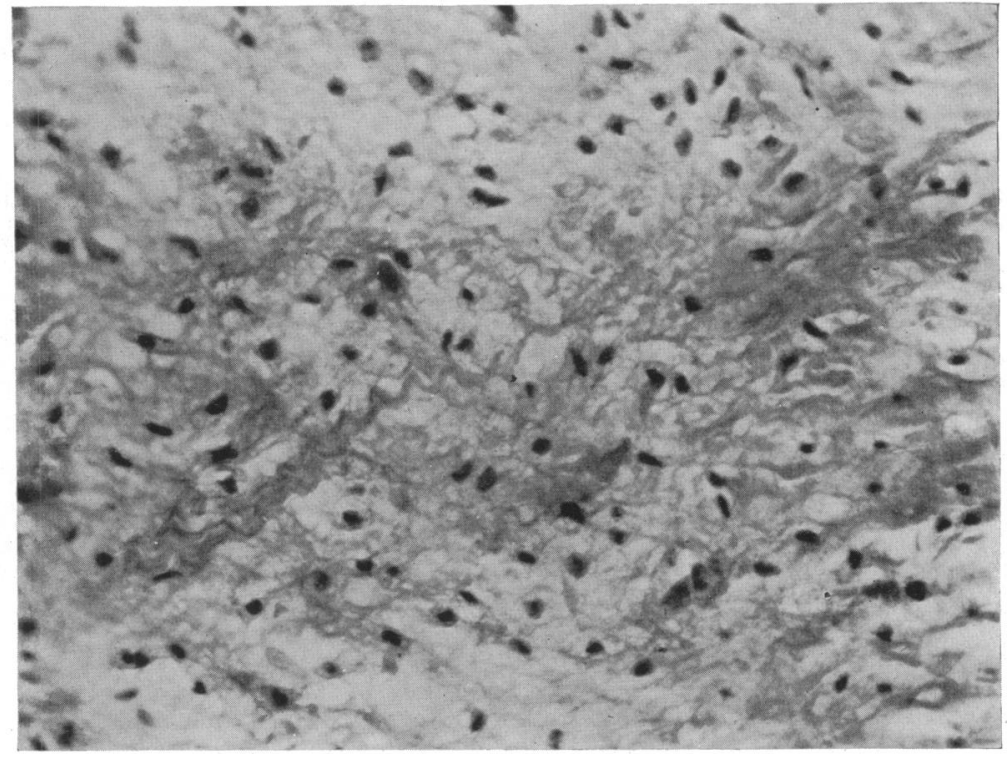

FIG. 7.-Endocardium showing fibrous thickening and cellular swelling. Magnification $\times 320$. Schiff's stain.

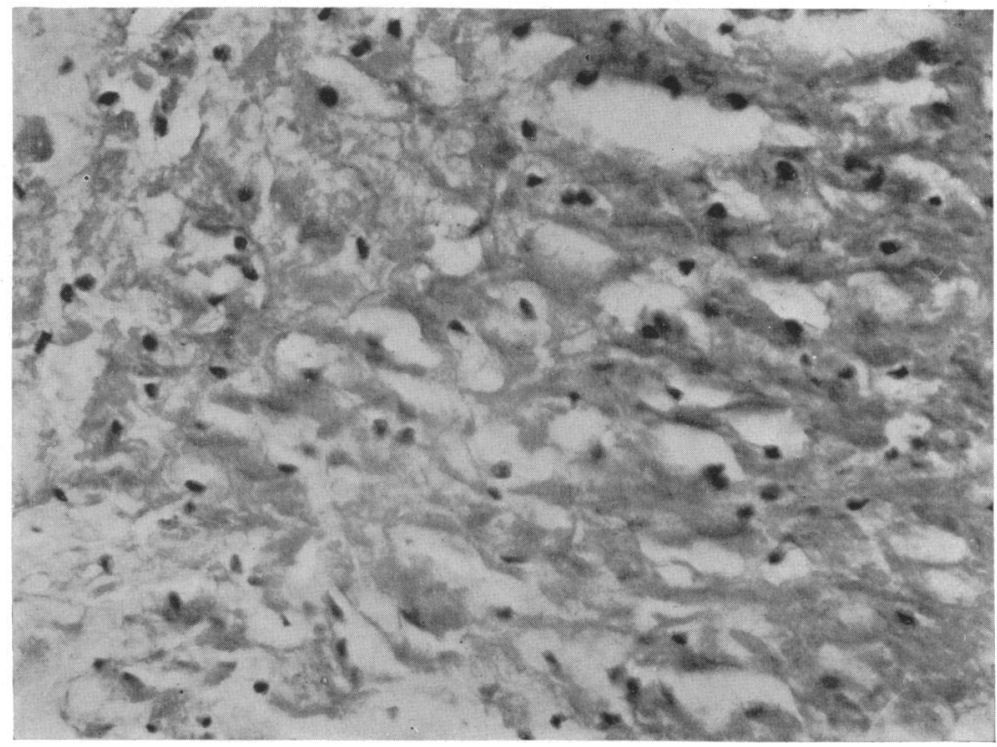

Fig. 8. - Base of aortic valve showing cellular swelling in connective tissue. Magnification $\times 320$. Schiff's stain 
pattern (Fig. 9). A large adventitial artery had a markedly thickened intima with similar histologic changes as already described. The media was atrophic and the lumen was narrowed (Fig. 10). Small interstitial hæmorrhages were present in the epicardial and myocardial layers. A few dark pink granules were seen in a few myocardial fibres with the Schiff stain (McManus, 1946).

There was marked vascular congestion of the lungs. There was abundant serous fluid in the alveolar spaces and interlobular septa. The latter also contained numerous large macrophages with vacuolated cytoplasm. There was no inflammatory reaction.

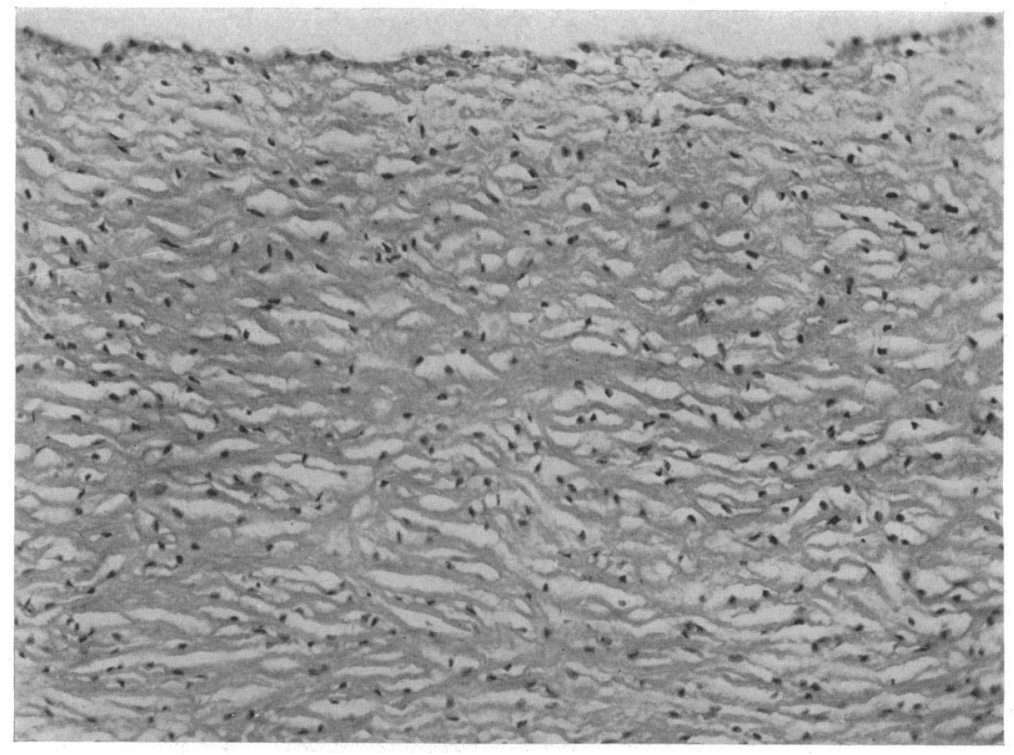

Fig. 9.-Aorta showing large clear connective tissue cells . Magnification $\times 80$. Schiff's stain.

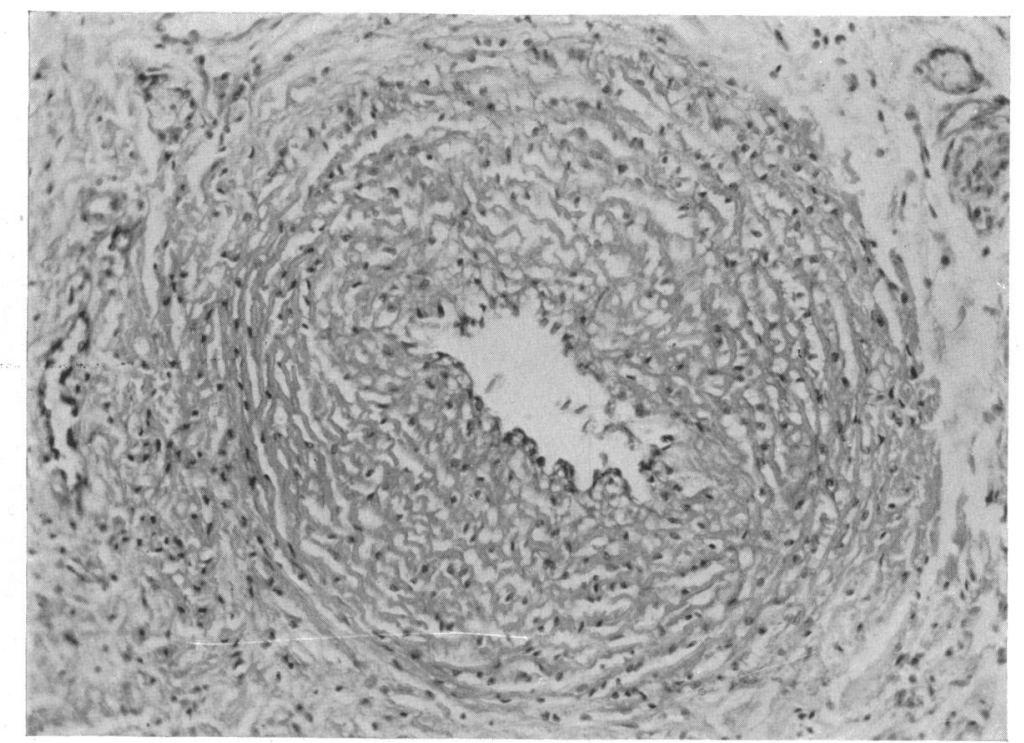

FIG. 10.-Small artery in aortic adventitia showing intimal thickening. Magnification $\times 80$. Schiff's stain. 
The hepatic cells were enlarged and had distinct cellular membranes (Fig. 11). The thin outer layer of cytoplasm was condensed and eosinophilic, while the inner portion was finely granular and vacuolated. The portal and central spaces were not altered, and there was no cirrhosis. The Schiff stain showed a few dark pink granules in a few of the Kupffer cells.

The splenic lymphoid follicles were large, poorly defined and had small germinal centres. In the splenic pulp many of the reticulo-endothelial cells were enlarged and had vacuolated cytoplasm. Portions of the basement membranes of the glomeruli were mildly thickened and frayed; cellularity was not increased. There was no alteration of the renal tubules, or of vascular or interstitial tissues. The gastroenteric tract showed nothing abnormal; the lymphoid tissue of the small intestine had a normal histologic appearance.

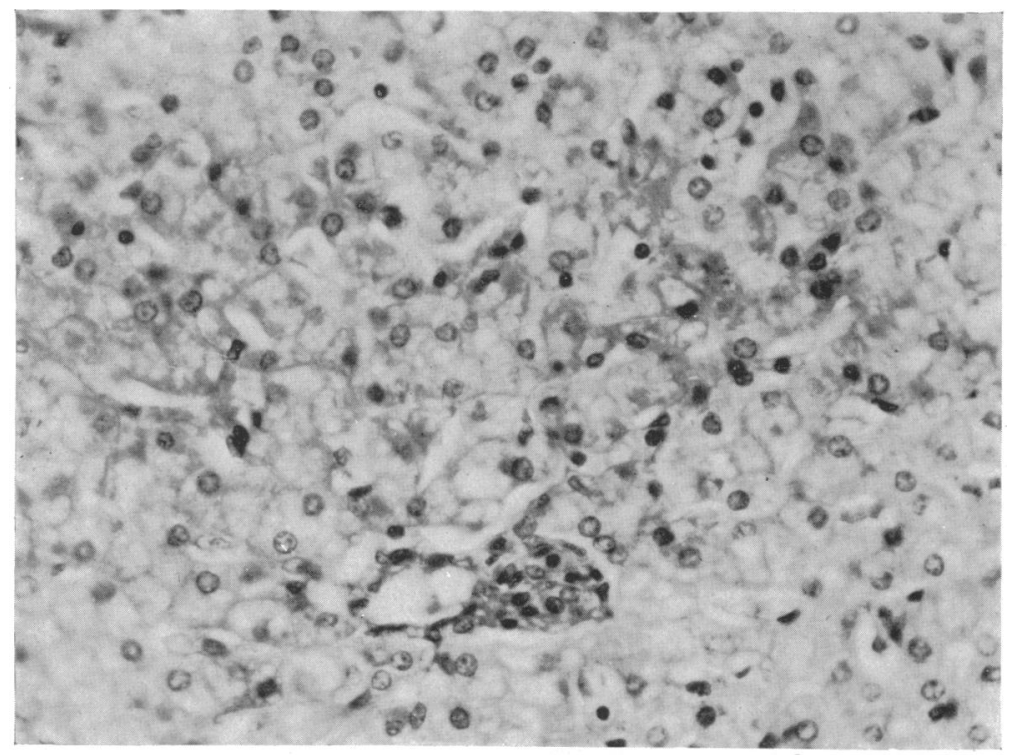

Fig. 11. - Liver showing vacuolization of hepatic cells. Magnification $\times 30$. Schiff's stain.

The adrenal cortical cells were normal. The medullary cells were enlarged. The nuclei were normal, but the cytoplasm was swollen, finely granular and vacuolated.

The thymic lobules were large and the cortex contained numerous lymphocytes. In the medulla were many large reticular cells with abundant foamy cytoplasm.

The sinusoids of several lymph nodes were lined by abnormal reticulo-endothelial cells. These were enlarged and had abundant vacuolated cytoplasm.

Numerous sections from all portions of the central nervous system showed no abnormalities. There were no changes in the nerve cells suggesting an abnormal storage process.

\section{SUMmaRY AND CONCLUSIONS}

In a review of 25 recorded autopsies in gargoylism there were 17 patients with gross or microscopic evidence of cardiovascular disease.

The average age of gargoyles dying of cardiac failure is approximately 11 years, with a range from 1 to 29 years. These fatal cases have shown the external manifestations of the disease, while the case reported in this paper appeared to present no characteristic external abnormalities. This case also differed from the others recorded in that the degree of cardiac and vascular involvement was greater than that of the other tissues. Although the liver, spleen, lymph-nodes, thymus, and adrenal gland all showed cytologic changes previously described in gargoylism, these organs 
were not enlarged or otherwise grossly altered. This case not only appears to be the youngest patient with gargoylism dying of cardiac failure, but also again demonstrates that the syndrome of gargoylism may have atypical or intermediate forms. The recording of otherwise typical cases, that however lacked corneal clouding or subnormal mentality, has already suggested the existence of such incomplete forms of the disease (Strauss, 1948).

The pathological lesions of the heart and vascular system are identical with those of other connective tissues, and consist of swelling and vacuolization of the cytoplasm of the connective tissue cells. The collagenous fibres in the affected tissues are swollen and often amorphous.

While all cardiac connective tissues are generally involved in the disease process, the most pronounced lesions are in the valves and coronary arteries. It is the alteration of these tissues that appears largely responsible for failure of the heart in many instances.

Of the fatal cases of gargoylism that have been reported, including the present one, the cause of death has been recorded in 19 cases; 14 of these appear to have died of cardiac failure.

Gargoylism should be considered in the diagnosis of cardiovascular disease in infants and children.

\section{REFERENCES}

Abramson, H., and Kurtz, L. D. (1946). Amer. J. Dis. Child., 72, 510.

Ashby, W. R., Stewart, R.M., and Watkins, J. H. (1937). Brain, 60, 149.

Berliner, M. L. (1939). Arch. Ophth., 22, 97.

Boecker, E. (1943). Zeitsch. Kinderheilkunde, 63, 688.

Cordes, F. C., and Hogan, M. J. (1942). Arch. Ophth., 27, 637.

Creveld, S. van (1939). Medicine, 18, 1.

DeLange, C. (1942). Psychiat. en Neurol. bl., 46, 2.

, Gerlings, P. G., deKleyn, A., and Lettinga, T. W. (1944). Acta. prediat., 31, 398.

Ellis, R. W. B., and Payne, W. P. (1936). Quart. J. Med., 29, 31.

Sheldon, W., and Capon, N. B. (1936). Ibid., 29, 119.

Gierke, E. von (1929). Beitr. path. Anat. allg., Pathol., 82, 497.

Halperin, S. L., and Curtis, G. M. (1942). Amer. J. Mental Def., 46, 298.

Haymond, J. L., and Giordano, A. S. (1946). Amer. J. Clin. Path., 16, 651.

Henderson, J. L. (1940). Arch. Dis. Child., 15, 201.

Hora, J. (1939-1940). Virchows Arch. path. Anat., 305, 298.

Hueper, W. C. (1942). Arch. Path., 33, 267.

Kny, W. (1942-1943). Z. Kinderh., 63, 366.

Kressler, R. J., and Aegerter, E. E. (1938). J. Pediat., 12, 579.

Lindsay, S. (1946). Amer. Heart J., 32, 419.

, Reilly, W. A., Gotham, T., and Skahen, R. (1948). Amer. J. Dis. Child., 76, 239.

Mason, H. H., and Andersen, D. H. (1941). Amer. J. Dis. Child., 61, 795.

McManus, J. F. A. (1946). Nature, 158, 202.

Nja, A. (1945-1946). Acta prediat., 33, 267.

Reilly, W. A. (1941). Amer. J. Dis. Child., 62, 489. and Lindsay, S. (1948). Ibid., 75, 595.

Rochat, G. F. (1942). Ophthalmologica, 103, 353.

Saphir, O. (1942). Amer. Heart J., 24, 167.

Schmidt, M. B. (1942). Zentralbl. allg. Path. path. Anat., 79, 113.

Stoeckel, K. H. (1941). Monatschr. Kinderh., 86, 348.

Straus, R., Merliss, R., and Reiser, R. (1947). Amer. J. Clin. Path., 17, 671.

Strauss, L. (1948). Amer. J. Path., 24, 855.

Tuthill, C. R. (1934). Arch. Neurol. Psychiat., 32, 198.

Washington, J. A. (1940), in Brennemann, J.: Practice of Pediatrics, Hagerstown, Md., W. F. Prior Company, Inc., Chap. 30.

Weiss, S. (1939). Med. Clin. North America, 23, 1323.

Stead, E. A., Jr., Warren, J. V., and Bailey, O. T. (1943). Arch. intern. Med., 71, 749.

Wolff, D. (1942). Laryngoscope, 52, 218. 